\title{
Impact of estimated solar radiation on gross primary productivity simulation in subtropical plantation in southeast China
}

\author{
Dengqiu Li ${ }^{\mathrm{a}, \mathrm{b}, *}$, Weimin Ju ${ }^{\mathrm{b}, *}$, Dengsheng Lu ${ }^{\mathrm{a}, \mathrm{c}}$, Yanlian Zhou ${ }^{\mathrm{d}}$, Huimin Wang ${ }^{\mathrm{e}}$ \\ ${ }^{a}$ Zhejiang Provincial Key Laboratory of Carbon Cycling in Forest Ecosystem and Carbon Sequestration, School of Environmental \& Resources \\ Sciences, Zhejiang A \& F University, Lin'an, Zhejiang Province 311300, China \\ ${ }^{\mathrm{b}}$ International Institute for Earth System Sciences, Nanjing University, Jiangsu Center for Collaborative Innovation in Geographic Information \\ Resource Development and Application, Nanjing, Jiangsu Province 210023, China \\ ${ }^{c}$ Center for Global Change and Earth Observations, Michigan State University, 1405 S. Harrison Road, East Lansing, MI 48864, USA \\ ${ }^{\mathrm{d}}$ School of Geographic and Oceanographic Sciences, Nanjing University, Nanjing, Jiangsu Province 210023, China \\ ${ }^{\mathrm{e}}$ Institute of Geographic Sciences and Natural Resources Research, Chinese Academy of Sciences, Beijing 100101, China
}

Received 13 February 2015; received in revised form 22 May 2015; accepted 16 July 2015

Available online 3 August 2015

Communicated by: Associate Editor Frank Vignola

\begin{abstract}
Sunshine duration is widely used to estimate solar radiation, but this estimated inherently contains some uncertainties, limiting its applications. This study investigated the impacts of the estimated solar radiation on simulated gross primary productivity (GPP), which were obtained using ecosystem models - light use efficiency model (LUE) and process-based model - Boreal Ecosystem Productivity Simulator (BEPS) at an evergreen coniferous forest ecosystem in southeast China. The models for solar radiation and diffuse radiation estimation were calibrated through observation data from nearby meteorological stations. The results showed that the established model could be successfully used to estimate solar radiation with high coefficient of determination (0.92) and low root mean square error $\left(2.18 \mathrm{MJ} \mathrm{m}^{-2} \mathrm{day}^{-1}\right)$, but the solar radiation was overestimated when the clearness index was less than 0.15 and underestimated when it was within the range of $0.2-0.35$ or greater than 0.6 . The estimated solar radiation has significant influence on the diffuse radiation estimation and GPP simulation comparing with using observations. The two ecosystem models reacted differently to the errors of estimated solar radiation. For the LUE model, the estimated solar radiation led to the underestimated GPP in growing season (May-October), and overestimated GPP during non-growing season (November-April) with the bias ranged from - $11 \%$ to $10 \%$ depending on the month of a year. For the BEPS model, estimated solar radiation resulted in overestimated GPP in most months with the bias ranged from $-6 \%$ to $20 \%$. The difference between the simulated GPP based on these two sources of solar radiation could be counteracted to some extent at the annual scale, especially for LUE model.
\end{abstract}

(c) 2015 Elsevier Ltd. All rights reserved.

Keywords: Sunshine duration; Solar radiation; Diffuse radiation; Gross primary productivity

\footnotetext{
* Corresponding authors at: Zhejiang Provincial Key Laboratory of Carbon Cycling in Forest Ecosystem and Carbon Sequestration, Zhejiang A \& F University, Lin'an, Zhejiang Province 311300, China. Tel.: +86 057163746360 (D. Li), International Institute for Earth System Sciences, Nanjing University, Nanjing, Jiangsu Province 210023, China. Tel.:+86 02589685670 (W. Ju).

E-mail addresses: lidengqiu001@163.com (D. Li), juweimin@nju.edu. cn (W. Ju).
}

\section{Introduction}

Forest ecosystem plays a pivotal role in the global carbon cycle and partially mitigates the rising atmospheric carbon dioxide $\left(\mathrm{CO}_{2}\right)$ concentration due to its role as a carbon sink (Pan et al., 2011). Understanding the forest 


\section{Nomenclature}

$a-e_{i} \quad$ coefficients in solar radiation and diffuse radiation estimation models

$\varepsilon_{\max } \quad$ maximum light use efficiency

$\Omega \quad$ clumping index

$A_{\text {canopy }}$ canopy-level photosynthesis

$A_{\text {sun }} \quad$ photosynthesis rates of sunlit leaf groups

$A_{s h} \quad$ photosynthesis rates of shaded leaf groups

APAR absorbed photosynthetically active radiation

BEPS Boreal Ecosystem Productivity Simulator

fPAR fraction of photosynthetically active radiation

GPP gross primary productivity

GPP $_{\mathrm{s}}$ simulated GPP by LUE and BEPS models

$\mathrm{GPP}_{\mathrm{e}} \quad$ estimated GPP from EC measurement

LUE light use efficiency model

$L_{\text {sun }} \quad$ sunlit leaf area

$L_{\text {sh }} \quad$ shaded leaf area

$L \quad$ total leaf area

LAI leaf area index

MBE
$N \quad$ number of observations

$Q_{\text {obs }} \quad$ observed values

$Q_{\text {est }} \quad$ estimated values

$R_{0} \quad$ extraterrestrial radiation on horizontal surface

$R^{2} \quad$ coefficient of determine

$R_{b} \quad$ directed radiation

$R_{d} \quad$ diffuse radiation

$R_{\text {de }} \quad$ diffuse radiation calculated from estimated solar radiation

$R_{\text {do }} \quad$ diffuse radiation calculated from observed solar radiation

RMSE root mean square error

$R_{S} \quad$ solar radiation

$R_{\text {se }} \quad$ estimated solar radiation

$S \quad$ sunshine duration

$S_{0} \quad$ day length

$T_{a} \quad$ minimum air temperature

$V P D \quad$ vapor pressure deficit carbon dynamics via ecosystem models is necessary for investigating the driving forces and mechanism of carbon sequestration (Pommerening et al., 2011; Richardson et al., 2012). Global solar radiation $\left(R_{s}\right)$ is an essential input variable to ecosystem models. It provides the primary energy source driving the physical and biochemical processes (transpiration and photosynthesis) of plant and determining forest gross primary productivity (GPP) (Mercado et al., 2009). Unfortunately, the continuous $R_{S}$ measurement is often not available at many forest regions (Adaramola, 2012; Liu et al., 2009a; Polo et al., 2015), and has to be estimated from other available meteorological observations (Angstrom, 1924; Besharat et al., 2013; Prescott, 1940; Yorukoglu and Celik, 2006). The impact of estimated $R_{s}\left(R_{\mathrm{se}}\right)$ on ecosystem models are mainly focused on the prediction of crop yields (cotton, maize, peanut, rice, etc.) around the world (Abraha and Savage, 2008; Garcia y Garcia et al., 2008; Phakamas et al., 2013; Trnka et al., 2007). However, fewer studies focused on the impact of $R_{\mathrm{se}}$ on the calculation of GPP in forest ecosystems, although these systems play an important role in global terrestrial carbon cycle.

The impacts of $R_{\text {se }}$ on the outcome of ecosystem models are related to the model structure. The overall effects of bias in $R_{\text {se }}$ might be canceled out because the biases are more or less normally distributed with a mean of zero and the relationships between $R_{s}$ biases and yield estimates are more or less linear (Pohlert, 2004; Xie et al., 2003). It was also found that $R_{\text {se }}$ produced deviations in excess of $\pm 25 \%$ in site-specific yield forecast because of the complexity of the model response (Trnka et al., 2007, 2005). In recent decades, a variety of models have been developed for calculating forest GPP at site, regional and global scales, embracing light use efficiency (LUE) models and process-based ecological models (Cai et al., 2014; Chen et al., 2012; Cramer et al., 2001; Running and Coughlan, 1988; Xiao et al., 2004). The LUE models, such as CASA (Potter et al., 1993), Global Production Efficiency Model (GLOPEM) (Prince and Goward, 1995), MOD17 algorithm (Running et al., 2000), VPM (Xiao et al., 2004), EC-LUE (Yuan et al., 2007), assuming that GPP be directly related to absorbed photosynthetically active radiation (APAR), which is calculated as the product of $R_{s}$ and fraction of photosynthetically active radiation (fPAR) (Yuan et al., 2014). They did not differentiate various responses of different leaves (sunlit and shaded leaves) to the environment and labeled as the "big-leaf" approach. The simulated GPP using these models is very sensitive to $R_{s}$ due to the linear relationship between GPP and $R_{s}$ (Yuan et al., 2014). For example, larger errors of these reanalysis radiation products (MERRA, ECMWF, and NCEP) resulted in larger uncertainty in GPP simulation comparing with these higher consistency satellite-derived radiation products (GLASS, ISCCP) in EC-LUE model (Cai et al., 2014). Another important GPP simulation strategy is to differ the sensitivity of carbon fixed by sunlit and shaded leaves to $R_{s}$, which named "two-leaf" model (Sprintsin et al., 2012). The sunlit leaves in the canopy are often light saturated as they both absorbed diffuse radiation $\left(R_{d}\right)$ and directed radiation $\left(R_{b}\right)$, whereas shaded leaves often suffer from a lower exposure to incoming radiation as only $R_{d}$ reached (Mercado et al., 2009). GPP simulation using this kind of models is affected not only by $R_{s}$ but also by the fractions of $R_{d}$ (Sprintsin et al., 2012). This implies that the accuracy of $R_{\text {se }}$ might have different impacts on "big-leaf" and "two-leaf" models. However, 
rarely research has been done to quantify the impact of $R_{\mathrm{se}}$ on outcomes of these different ecosystem models at the same forest site.

Previous studies indicated that the conversion from sunshine duration to $R_{s}$ produces better estimates than other approaches and variables (Adaramola, 2012; Trnka et al., 2005; Yorukoglu and Celik, 2006). As $R_{s}$ was observed at 92 radiation stations in China, accounting for only $13 \%$ of observed sunshine duration at 753 national basic meteorological stations. $R_{S}$ was normally estimated from sunshine duration and used to calculate diffuse radiation in the calculation of carbon budget of forest ecosystems in China (Ju et al., 2010a; Liu et al., 2014). However, the performance of the $R_{s e}$ and $R_{d}$ was not systematically evaluated. The subtropical forest ecosystem of China has been proved to be one of the highest carbon uptakes of forests worldwide, and represented another large carbon uptake region (Yu et al., 2014). Radiation is the main constraint of photosynthesis in these areas due to the frequently rainy and/or cloudy days, which also considerably influences the accuracy of radiation estimation from sunshine duration. How errors in $R_{\mathrm{se}}$ affected GPP simulation for the forest ecosystems have not been thoroughly investigated.

The objectives of this study are to investigate: (1) the performance of sunshine duration based on solar radiation estimation in subtropical forest area in southeast China; (2) the difference between the diffuse radiation estimated from observed solar radiation and diffuse radiation estimated from estimated solar radiation; (3) the impact of estimated solar radiation on GPP simulation in LUE model (MOD17 algorithm, big-leaf model) and process-based model (Boreal Ecosystem Productivity Simulator, BEPS, two-leaf model) and the differences between these models.

\section{Materials and methods}

\subsection{Data used}

\subsubsection{Measurements of sunshine duration, solar radiation, and diffuse radiation}

Measurements over the period of 2000-2006 at six meteorological stations (Fig. 1) in southeast China were used to examine the relationship between daily sunshine duration and daily $R_{s}$. Sunshine duration was measured with the Jordan sunshine recorder. $R_{S}$ was measured using automatic telemetering radiometer (thermoelectric type, special optical black paint for induction surface) with relative error of $\pm 0.5 \%$. Data quality control was conducted for each station using the same standard. Further check of outliers was done in this study. No more than four outliers in each year were found and were replaced by the average values on two adjacent days. Information about six sites is presented in Table 1. Diffuse radiation observed at ShangHai, WuHan, and GuangZhou was used to establish the function for partitioning $R_{d}$ from $R_{s}$.

\subsubsection{Flux data measured at Qianyanzhou site}

Flux data measured at Qianyanzhou was used for ecosystem model validation. This site is located at Jiangxi Province of southeast China, a typical evergreen coniferous plantation forest ecosystem with subtropical monsoon climate (Fig. 1). The mean annual temperature was $19.0^{\circ} \mathrm{C}$ and annual precipitation was $1394.7 \mathrm{~mm}$ during 1985 2010. The forest, which was planted in 1985, is dominated by Slash pine (Pinus elliottii), Masson pine (Pinus massoniana) and Chinese fir (Cunninghamia lanceolata), with a tree density of about 1460 stems ha ${ }^{-1}$. The eddy flux observation system has been in operation since late 2002 .

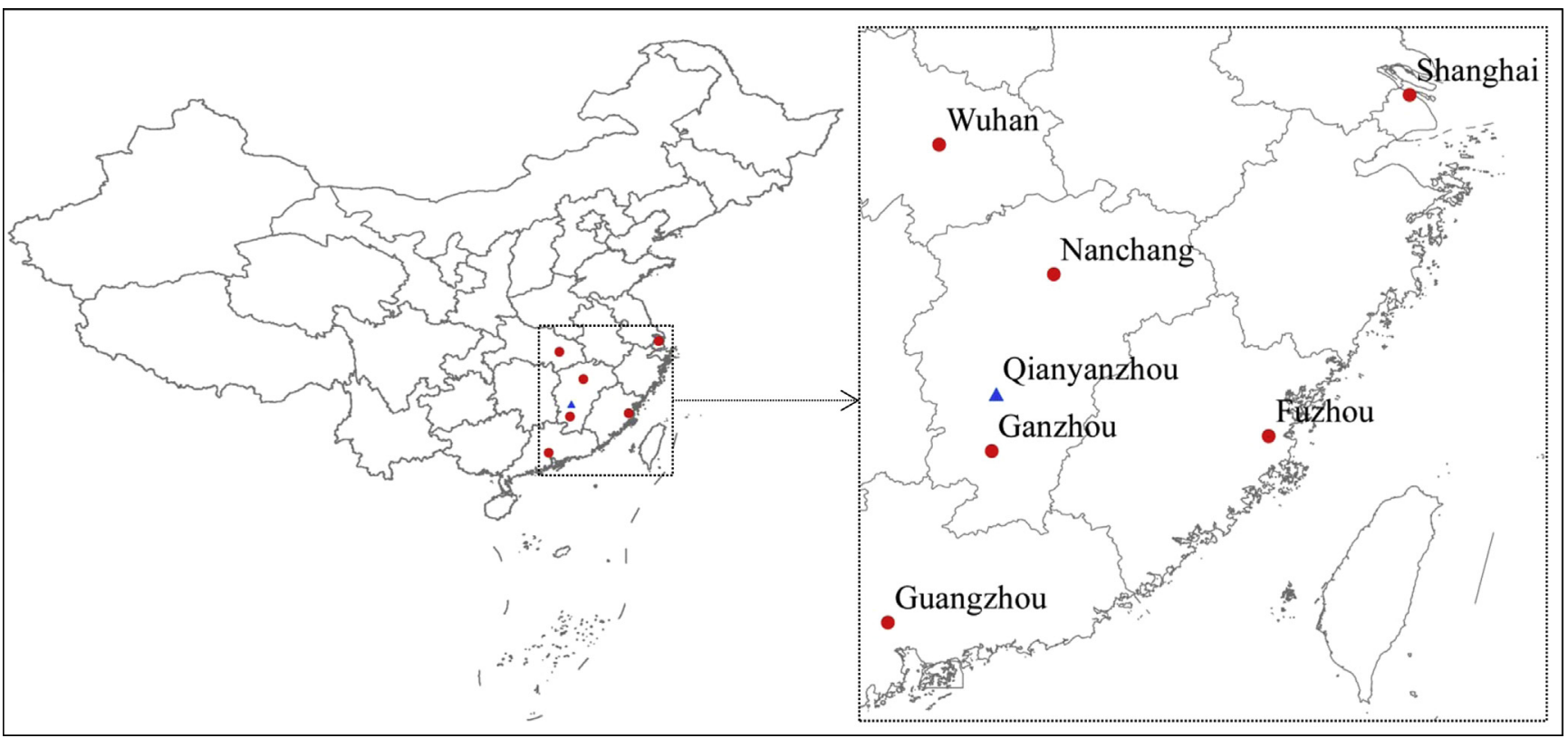

Fig. 1. Locations of six meteorological stations and Qianyanzhou eddy tower flux site. 
Table 1

Geographic and average radiation of the six meteorological stations and eddy tower site.

\begin{tabular}{|c|c|c|c|c|c|}
\hline Station name & Latitude $\left({ }^{\circ} \mathrm{N}\right)$ & Longitude $\left({ }^{\circ} \mathrm{E}\right)$ & Sunshine duration (h day ${ }^{-1}$ ) & Solar radiation $\left(\mathrm{MJ} \mathrm{m}^{-2} \mathrm{day}^{-1}\right)$ & Diffuse radiation $\left(\mathrm{MJ} \mathrm{m}^{-2} \mathrm{day}^{-1}\right)$ \\
\hline Shanghai & 31.40 & 121.48 & $5.0(4.0)$ & $12.3(7.2)$ & $7.1(3.4)$ \\
\hline Wuhan & 30.62 & 114.13 & $5.0(4.2)$ & $11.8(7.5)$ & $7.4(3.7)$ \\
\hline Nanchang & 28.60 & 155.92 & $5.2(4.4)$ & $12.0(7.8)$ & $\mathrm{N} / \mathrm{A}^{\mathrm{a}}$ \\
\hline Fuzhou & 26.08 & 119.28 & $4.5(4.0)$ & $12.3(7.2)$ & $\mathrm{N} / \mathrm{A}^{\mathrm{a}}$ \\
\hline Guangzhou & 25.85 & 114.95 & $4.8(3.7)$ & $12.3(5.8)$ & $7.2(2.9)$ \\
\hline Ganzhou & 23.17 & 113.33 & $4.4(4.2)$ & $11.8(7.5)$ & $\mathrm{N} / \mathrm{A}^{\mathrm{a}}$ \\
\hline Qianyanzhou & 26.73 & 115.02 & $4.7(4.2)$ & $12.1(7.6)$ & $\mathrm{N} / \mathrm{A}^{\mathrm{a}}$ \\
\hline
\end{tabular}

${ }^{a}$ Diffuse radiation was not observed. Values in parentheses are standard deviation.

Daily observed GPP data was used to evaluate the performance of LUE and BEPS models and calculated as the summation of 30-min measurements of GPP. It equals net ecosystem productivity (NEP) plus ecosystem respiration (ER), which was estimated using air/soil temperature and the Lloyd-Taylor equation fitted with nighttime measured NEP (Yu et al., 2008).

\subsubsection{Leaf area index used to drive models}

Leaf area index (LAI) is required to drive the LUE and BEPS models. It was inverted with the algorithm developed by Deng et al. (2006) and the MODIS products of BRDF (MCD 43A1) and surface reflectance (MOD 09A1). This LAI inversion algorithm was developed based on the Four-Scale geometrical model and was able to produce high quality of LAI in various ecosystems (Liu et al., 2012). The inverted LAI was further smoothed using a Locally Adjusted Cubic-spline Capping (LACC) method to remove the effects of residual cloud and aerosol contamination (Chen et al., 2006).

\subsection{Solar radiation and diffuse radiation estimation models}

\subsubsection{Estimation of solar radiation using sunshine duration}

The Ångström-Prescott equation, which calculates $R_{S}$ as a function of the extraterrestrial radiation on horizontal surface $\left(R_{0}\right)$ has been widely used (Bakirci, 2009; Besharat et al., 2013; Liu et al., 2009b). Meanwhile, many alternative models have been proposed for calculating $R_{s}$ based on sunshine duration measurements (Besharat et al., 2013). Here, four commonly used models were tested:

Linear model (Ångström-Prescott model, (Prescott, 1940)):

$\frac{R_{s}}{R_{0}}=a_{1}+b_{1} \times \frac{S}{S_{0}}$

Exponential model (Almorox and Hontoria, 2004):

$\frac{R_{s}}{R_{0}}=a_{2}+b_{2} \times \exp \left(\frac{S}{S_{0}}\right)$

Quadratic model (Ögelman et al., 1984):

$\frac{R_{s}}{R_{0}}=a_{3}+b_{3} \times \frac{S}{S_{0}}+c_{3} \times\left(\frac{S}{S_{0}}\right)^{2}$

Linear exponential model (Bakirci, 2009):
$\frac{R_{s}}{R_{0}}=a_{4}+b_{4} \times \frac{S}{S_{0}}+c_{4} \times \exp \left(\frac{S}{S_{0}}\right)$

where $a_{i}, b_{i}$, and $c_{i}(i=1,2,3$, and 4$)$ are coefficients, which were fitted using Levenberg-Marquardt method (Moré, 1978). $S$ and $S_{0}$ represent sunshine duration $(h)$ and day length $(h)$, respectively. Calculation of $R_{0}$ and $S_{0}$ can be refer to Yorukoglu and Celik (2006) and its related references. The best model was used to estimate $R_{s}$ using sunshine duration for Qianyanzhou site.

\subsubsection{Estimation of diffuse radiation using empirical equations}

Diffuse radiation $\left(R_{d}\right)$ is rarely measured, and often estimated from global radiation and the fraction of $R_{d}$, which can be estimated according to clearness index $\left(R_{s} / R_{0}\right)$, sunshine percentage and cloud cover (Boland et al., 2008; Cotfas et al., 2014; Liu and Jordan, 1960; Reindl et al., 1990; Rivington et al., 2008). Clearness index is defined as the ratio of the daily terrestrial global radiation on a horizontal surface to the daily extraterrestrial radiation on that surface and correlated with daily diffuse fraction (Liu and Jordan, 1960). In this study, three commonly used $R_{d}$ partitioning models were tested and the best-performed model would be used for estimating $R_{d}$ of Qianyanzhou site. These models are:

Linear model (Reindl et al., 1990):

$\frac{R_{d}}{R_{s}}=a_{5}+b_{5} \times \frac{R_{s}}{R_{0}}+c_{5} \times \cos \theta$

Forth power polynomial model (Erbs et al., 1982):

$$
\begin{aligned}
\frac{R_{d}}{R_{s}}= & a_{6}+b_{6} \times \frac{R_{s}}{R_{0}}+c_{6} \times\left(\frac{R_{s}}{R_{0}}\right)^{2}+d_{6} \times\left(\frac{R_{s}}{R_{0}}\right)^{3}+e_{6} \\
& \times\left(\frac{R_{s}}{R_{0}}\right)^{4}
\end{aligned}
$$

Logistic model (Boland et al., 2008):

$\frac{R_{d}}{R_{s}}=\frac{1}{1+e^{a_{7}+b_{7} \times R_{s}}}$

where $a_{i}, b_{i}, c_{i}, d_{i}$, and $e_{i}(i=5,6$, and 7$)$ are the coefficients fitted using observations, $\theta$ is the solar zenith angle. $R_{d}, R_{s}$, and $R_{0}$ represent daily diffuse radiation $\left(\mathrm{MJ} \mathrm{m}^{-2} \mathrm{day}^{-1}\right)$, daily solar radiation $\left(\mathrm{MJ} \mathrm{m}^{-2} \mathrm{day}^{-1}\right)$ and daily 
extraterrestrial radiation on horizontal surface $\left(\mathrm{MJ} \mathrm{m}^{-2}\right.$ day $\left.^{-1}\right)$, respectively.

\subsection{Models used for simulating GPP}

GPP at Qianyanzhou site for the period between 2003 and 2005 was simulated using the MOD17 algorithm and the BEPS model. They were both driven by $R_{s}$ (observed solar radiation) and $R_{\text {se }}$ (estimated solar radiation) along with other meteorological inputs (including maximum and minimum temperature, precipitation, and relative humidity). The two models have been proved suitable for the subtropical area (He et al., 2013).

\subsubsection{LUE model}

The MOD17 algorithm was taken as a representative of LUE models. It calculates APAR on the basis of Beer's law (Jarvis and Leverenz, 1983) and remotely sensed LAI and integrates the effects of minimum temperature and water vapor deficit on light use effciency. GPP is calculated as (Running et al., 2000):

$G P P=\varepsilon_{\max } f(V P D) g\left(T_{a}\right) f P A R \cdot P A R$

where $\varepsilon_{\max }$ is the maximum light use efficiency, $f(V P D)$ and $g\left(T_{a}\right)$ are the scalars of vapor pressure deficit $(V P D)$ and the minimum air temperature $\left(T_{a}\right), f P A R$ is the fraction of $P A R$ (photosynthetically active radiation) absorbed by the canopy. Parameters in Eq. (8) was set following $\mathrm{He}$ et al. (2013).

\subsubsection{BEPS model}

The BEPS model used here is a daily process-based model (Liu et al., 1999) that computes the canopy-level photosynthesis $\left(A_{\text {canopy }}\right)$ as the sum of sunlit and shaded leaf groups using the Farquhar's instantaneous photosynthesis model (Farquhar et al., 1980):

$A_{\text {canopy }}=A_{\text {sun }} L_{\text {sun }}+A_{\text {sh }} L_{\text {sh }}$

where $A_{\text {sun }}$ and $A_{\text {sh }}$ are the photosynthesis rates of sunlit and shaded leaf groups through a simplified analytical temporal integration (Chen et al., 1999), $L_{s u n}$ and $L_{s h}$ are the sunlit leaf area and shaded leaf area. They are separated from total LAI $(L)$ (Chen et al., 1999):

$L_{\text {sun }}=2 \cos \theta\left(1-e^{-0.5 \Omega L / \cos \theta}\right)$

$L_{s h}=L-L_{\text {sun }}$

where $\Omega$ is the clumping index. The inputs to the BEPS model include LAI, daily meteorological variables (maximum temperature, minimum temperature, solar radiation, precipitation, and relative humidity), and soil texture. Parameters here are referenced Ju et al. (2010b).

\subsection{Criteria of model performance}

Uncertainty was defined as the difference between model estimates of solar radiation from sunshine duration, diffuse radiation and GPP arising from the use of observed site specific solar radiation data and estimated data following Rivington et al. (2006) and Wang et al. (2015). The performance of models was assessed using the coefficient of determine $\left(R^{2}\right)$, mean bias error (MBE), and root mean square error (RMSE). They are calculated as:

$R^{2}=\frac{\left(\sum\left(Q_{o b s}-\overline{Q_{o b s}}\right)\left(Q_{e s t}-\overline{Q_{e s t}}\right)\right)^{2}}{\sum\left(Q_{o b s}-\overline{Q_{o b s}}\right)^{2} \sum\left(Q_{e s t}-\overline{Q_{e s t}}\right)^{2}}$

$\mathrm{MBE}=\frac{\sum\left(Q_{o b s}-Q_{e s t}\right)}{N}$

$\mathrm{RMSE}=\sqrt{\frac{\sum\left(Q_{o b s}-Q_{\text {est }}\right)^{2}}{N}}$

where $Q_{o b s}$ and $Q_{\text {est }}$ are the observed and estimated values for assessing $R_{\mathrm{se}}$. In the assessment of estimated GPP and diffuse radiation, they denote the estimates using $R_{s}$ and $R_{\mathrm{se}} . N$ is the number of observations. The $t$ test was used to determine if the simulated and observed $R_{s}, R_{d}$ or GPP were significantly different from each other at a particular confidence level.

\section{Results}

\subsection{Characteristic of radiation in subtropical area of China}

Fig. 2 demonstrates the seasonal variations of monthly $R_{s}$, sunshine duration, $R_{d}$ and clearness distribution of six meteorological stations in southeast China. The $R_{S}$ showed single peak variation with the maximum in July and relatively smooth trend of seasonal change. The maximum sunshine duration occurred in July consistent with that of $R_{s}$. However, the sunshine duration showed less variation during March-June than that of $R_{s}$, and declined obviously from July to August. The 25th percentile values of sunshine duration showed that there were a large proportion of days with the sunshine duration equal to 0 , especially in non-growing season (from November to May). It indicates that many days with different $R_{S}$ could not be differentiated by sunshine duration because of the insensitive sunshine recorder in the subtropical area of China. The $R_{d}$ showed strongly seasonal patterns as the maximum in June. The clearness index values had the largest frequency around 0.55 . The frequency of lower clearness index that was less than 0.2 also accounted for a higher proportion as the rainy season was in the first half year.

\subsection{Assessment of global solar radiation estimation}

Parameters in four $R_{S}$ estimation models were calibrated using measures from six meteorological stations during 2000 to 2006. Table 2 shows the performance of four models to establish the relationships between $R_{s}$ and sunshine duration. The quadratic model performed best with the lowest RMSE and the highest $R^{2}$. The linear model performed slightly better than exponential model. All the models underestimated the $R_{S}$ with the MBE in the range 

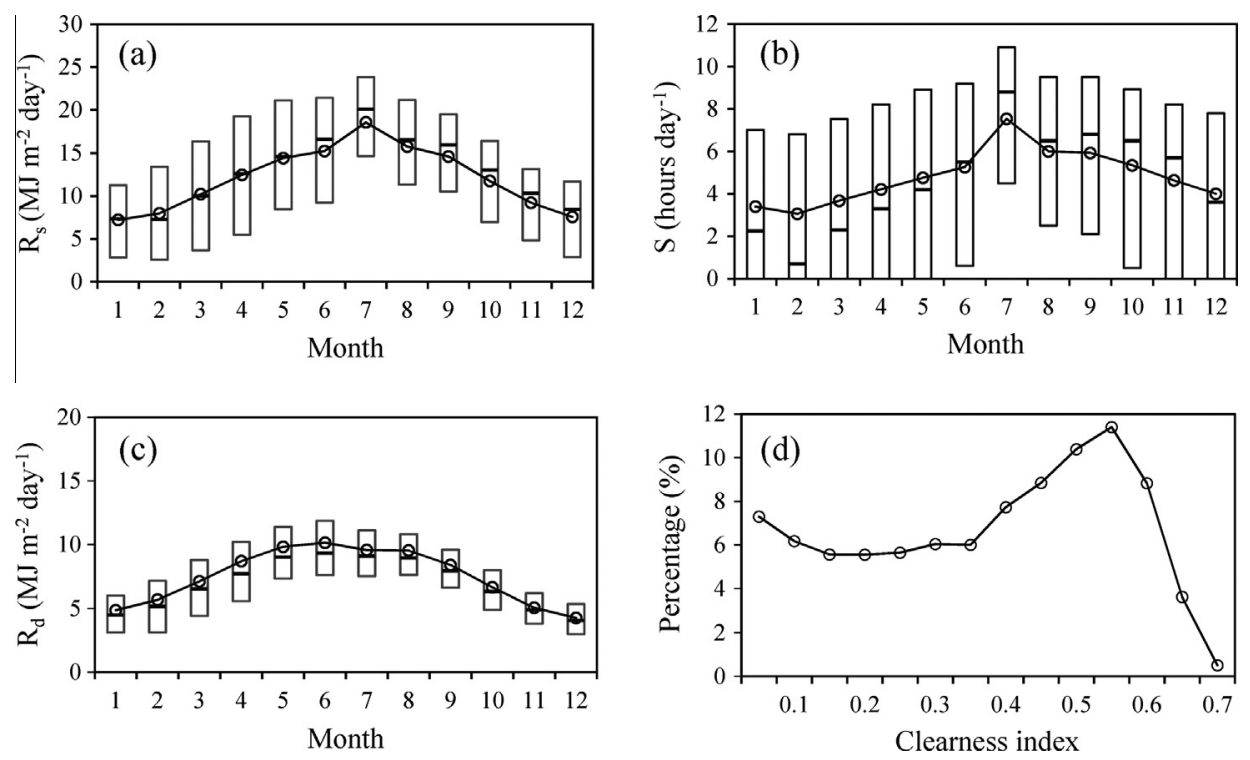

Fig. 2. Seasonal variations of monthly mean solar radiation (a), sunshine duration (b), diffuse radiation (c), and frequency distribution of clearness index (d) during 2000-2006 in southeast China. The boundary of boxes indicates 25th and 75th percentile, line and circle within boxes mark median and mean.

Table 2

Summary of estimated solar radiation against observed solar radiation $\left(\mathrm{MJ} \mathrm{m}^{-2} \mathrm{day}^{-1}\right)$.

\begin{tabular}{lcllll}
\hline Model & \multicolumn{2}{c}{ Coefficients } & & MBE & RMSE \\
\cline { 2 - 4 } & $a_{i}$ & $b_{i}$ & $c_{i}$ & & \\
\hline Linear model & 0.150 & 0.556 & - & -0.062 & 2.292 \\
Exponential model & -0.184 & 0.353 & - & -0.081 & 2.566 \\
Quadratic model & 0.133 & 0.814 & -0.317 & -0.048 & 2.178 \\
Linear exponential model & 0.513 & 1.139 & -0.378 & -0.051 & 0.898 \\
\hline
\end{tabular}

of -0.081 to $-0.048 \mathrm{MJ} \mathrm{m}^{-2} \mathrm{day}^{-1}$. The quadratic model and corresponding coefficients were used for obtaining $R_{\text {se }}$ at Qianyanzhou site.

The 2003-2005 daily $R_{\text {se }}$ of Qianyanzhou site was compared with the $R_{S}$ observations from the eddy tower. The quadratic model performed well with the values of $R^{2}$ 0.92 and RMSE $2.18 \mathrm{MJ} \mathrm{m}^{-2} \mathrm{day}^{-1}$ (Fig. 3), and there

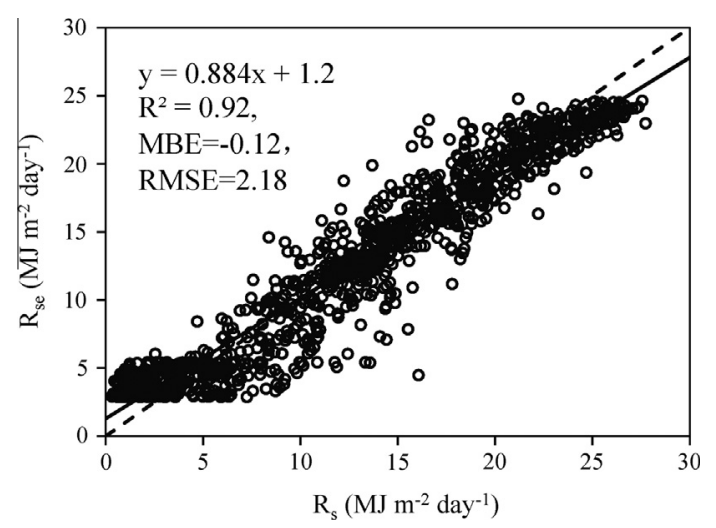

Fig. 3. Comparison between $R_{s}$ and $R_{\mathrm{se}}$ at Qianyanzhou site during $2003-$ 2005. Dashed line shows the 1:1 line. Solid line shows the regression line. ( $R_{s}$ : observed solar radiation; $R_{\mathrm{se}}$ : estimated solar radiation based on the sunshine duration and quadratic model). was no significant difference between two datasets according to the $t$ test $(p=0.074)$. The MBE value showed the $R_{\text {se }}$ was more serious underestimated by quadratic model at Qianyanzhou site than in the six meteorological stations, and presented obviously seasonal variations during 20032005. The $R_{\text {se }}$ was underestimated during the period of May-October and overestimated during the period from December to March (Fig. 4a). The RMSE of $R_{\text {se }}$ was larger in the growing season than in non-growing season. Due to the inter-annual variation of meteorological variables, the monthly RMSE peaked at different time during 20032005. The cloudiness condition significantly impacted the accuracy of $R_{\text {se }}$ (Fig. 4b). The model overestimated $R_{\text {se }}$ during days with clearness index below 0.15 and underestimated $R_{\text {se }}$ on days with clearness index in the range of 0.2 0.4 and higher than 0.6. The RMSE approached the largest values under the conditions of clearness index about 0.35 and the least around 0.15 and 0.6 .

\subsection{Assessment of diffuse radiation estimation}

Three $R_{d}$ estimation models showed similar performances at three meteorological stations (Shanghai, Wuhan, and Guangzhou) with observation data during 2000-2006 (Table 3). The linear model slightly 

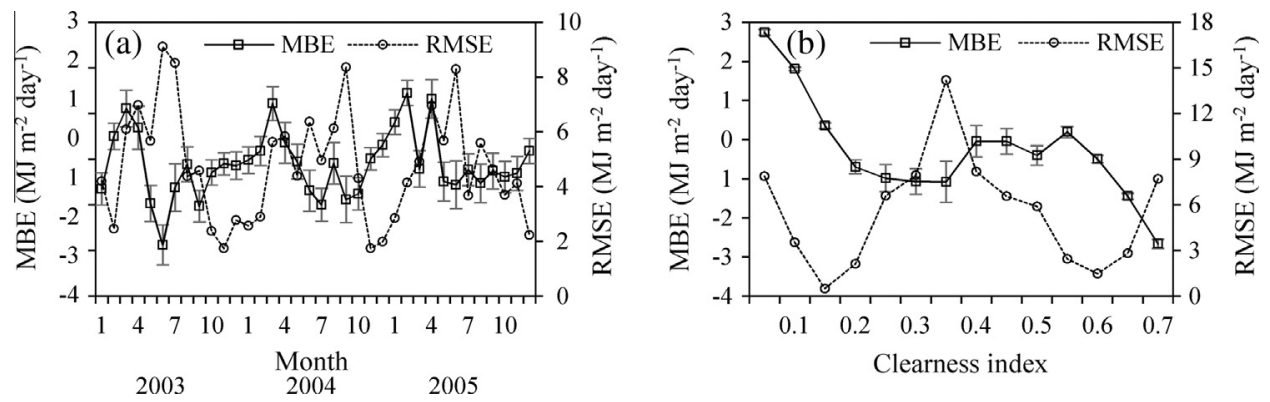

Fig. 4. Changes of mean bias error (MBE) and root mean square error (RMSE) of $R_{\mathrm{se}}$ with months and clearness index at Qianyanzhou site. The error bars denote the standard error of the mean.

Table 3

Summary of estimated against observed diffuse radiation $\left(\mathrm{MJ} \mathrm{m}^{-2} \mathrm{day}^{-1}\right)$.

\begin{tabular}{llllllrr}
\hline Model & \multicolumn{2}{l}{ Coefficients } & & & MBE & RMSE & $R^{2}$ \\
\cline { 2 - 6 } & $a_{i}$ & $b_{i}$ & $c_{i}$ & $d_{i}$ & $e_{i}$ & \\
\hline Linear model & 1.273 & 1.552 & 0.052 & - & - & 0.07 & 1.08 \\
Forth power polynomial model & 0.680 & 3.465 & -13.725 & 16.317 & -7.387 & -0.01 & 1.07 \\
Logistic model & 3.980 & 7.453 & - & - & - & 0.90 \\
\hline
\end{tabular}

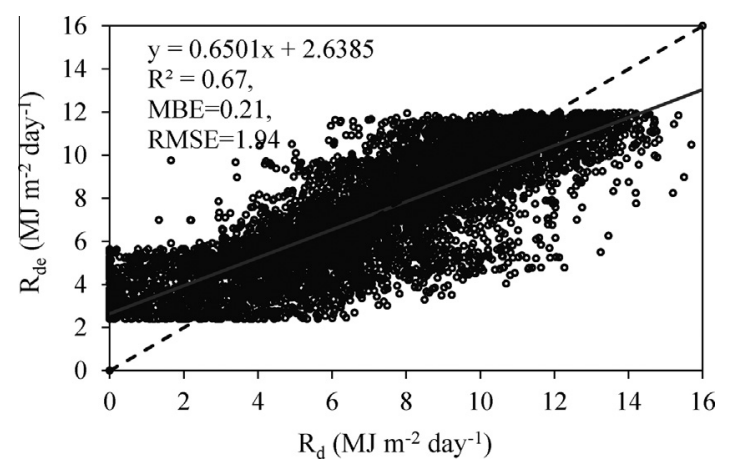

Fig. 5. Comparison between observations $\left(R_{d}\right)$ and estimated diffuse radiation $\left(R_{\mathrm{de}}\right)$ using the Logistic model in conjunction with $R_{\mathrm{se}}$ (Shanghai, Wuhan, Guangzhou) during 2000-2006. Dashed line shows the 1:1 line. Solid line shows the regression line.

overestimated $R_{d}$ comparing to other two models. Considering less coefficients of the Logistic model, it was chosen for further analysis, i.e. to test the impact of $R_{\mathrm{se}}$ on $R_{d}$ estimation and GPP simulation. Table 3 and Fig. 5 reveal that $R_{\mathrm{se}}$ significantly impacted $R_{d}$ estimation with the $R^{2}$ and RMSE changed from 0.90 and $1.07 \mathrm{~m}^{-2}$ day $^{-1}$ to 0.67 and $1.94 \mathrm{MJ} \mathrm{m}^{-2}$ day $^{-1}$, when $R_{s}$ was substituted by $R_{\mathrm{se}}$. The $t$ test indicated there was significant difference between the two mean values of $R_{d}$ and estimated $R_{d}$ from $R_{\text {se }}\left(R_{\mathrm{de}}\right)(p<0.01)$. The scatter plot shows that $R_{\mathrm{de}}$ was overestimated for lower $R_{d}$ and underestimated for higher $R_{d}$, and with an overall overestimation $0.21 \mathrm{MJ} \mathrm{m}^{-2}$ day $^{-1}$ (Fig. 5).

$R_{d}$ was calculated based on $R_{s}$ and $R_{\mathrm{se}}$ to clarify the differences between two sources of solar radiation based estimation at Qianyanzhou site during 2003-2005. Due to lack of $R_{d}$ observation data, the $R_{d}$ calculated from $R_{s}\left(R_{\mathrm{do}}\right)$ was treated as truth. $R_{\mathrm{de}}$ could explain $81 \%$ variation with the

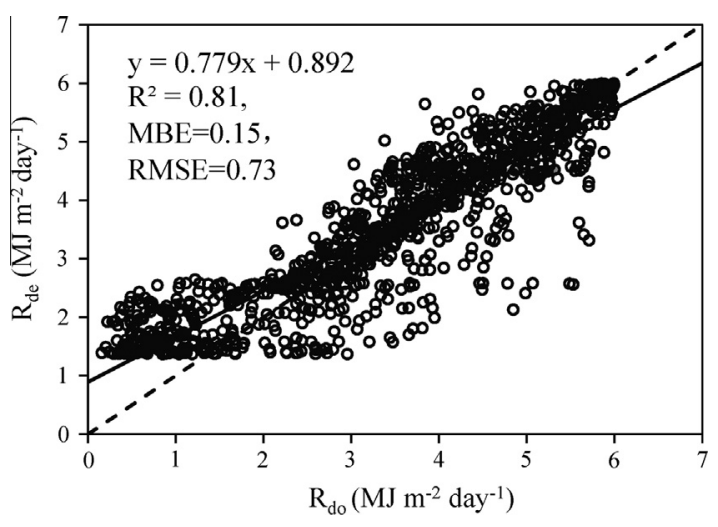

Fig. 6. Comparison of estimated diffuse radiation values by Logistic with two sources of solar radiation at Qianyanzhou site during 2003-2005. Dashed line shows the 1:1 line. Solid line shows the regression line. $\left(R_{\mathrm{do}}\right.$ : estimated diffuse radiation from $R_{s} ; R_{\mathrm{de}}$ : estimated diffuse radiation from $R_{\text {se) }}$.

MBE and RMSE values of 0.15 and $0.73 \mathrm{MJ} \mathrm{m}^{-2} \mathrm{day}^{-1}$ (Fig. 6). $R_{\mathrm{de}}$ was overestimated under low $R_{d}$ and underestimated under high $R_{d}$ comparing with $R_{\mathrm{do}}$, and there were many deviations points during all $R_{d}$ ranges. The $t$ test indicated the two sources of data was significantly different $(p<0.01)$. Most months' $R_{\mathrm{de}}$ was overestimated with the peak occurred in spring during 2003-2005 (Fig. 7). The MBE change trend of $R_{\mathrm{de}}$ was consistent with that of $R_{\mathrm{se}}$. However, it should be noted that a serious underestimation in $R_{\mathrm{se}}$ did not definitely induced an underestimation in $R_{\mathrm{de}}$, e.g. April in 2003. RMSE was higher in the first half year and was relative higher in 2003 and $2005 . R_{\text {de }}$ was overestimated under the condition of clearness index less than 0.15 and larger than 0.6 , and was underestimated in the range of 0.2-0.55. Both maximum MBE and RMSE occurred under the case of extreme low clearness index. 

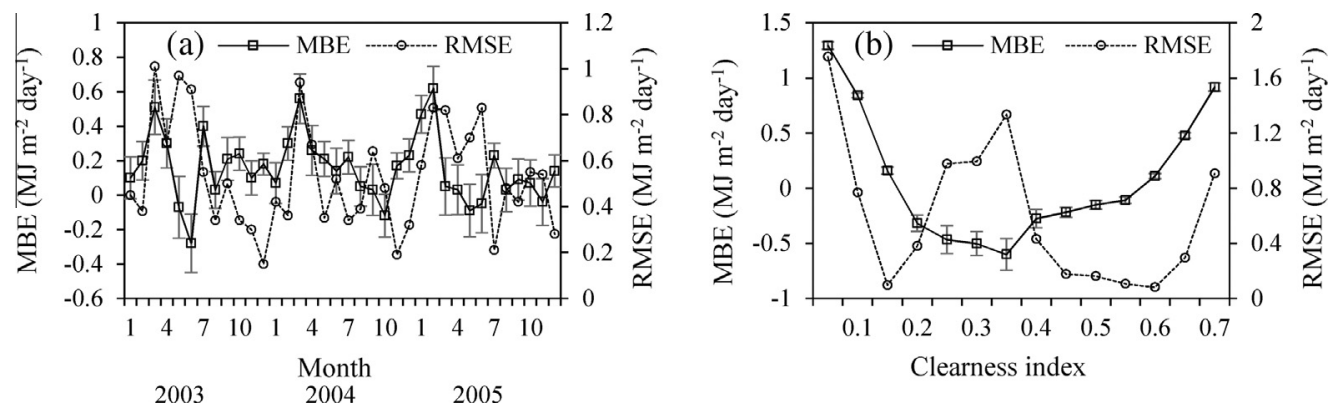

Fig. 7. Comparisons of estimated diffuse radiation ( $R_{\mathrm{de}}$ VS. $\left.R_{\mathrm{do}}\right)$ from two sources of solar radiation $\left(R_{s}\right.$ and $\left.R_{\mathrm{se}}\right)$ with months and clearness index. The error bars denote the standard error of the mean. ( $R_{\mathrm{do}}$ was taken as the truth due to lack of observed diffuse radiation).

\subsection{Impact of estimated solar radiation on GPP simulation}

Compared with the estimated GPP $\left(\mathrm{GPP}_{\mathrm{e}}\right)$ based on eddy tower measurements, the simulated GPP $\left(\mathrm{GPP}_{\mathrm{s}}\right)$ driven by $R_{s}$ with the BEPS model exhibited best performance with the lowest RMSE and the highest $R^{2}$ (Fig. 8). The BEPS model driven by $R_{\text {se }}$ performed even better than that of LUE model driven by $R_{s}$ as indicated by lower RMSE and higher $\mathrm{R}^{2}$. However, the $\mathrm{GPP}_{\mathrm{s}}$ from BEPS model was considerably overestimated comparing with that of LUE model indicating by the MBE values, and the $R_{\mathrm{se}}$ intensified this overestimation with the relative MBE increased from $3 \%$ to $6 \%$ in BEPS model. $R_{\text {se }}$ led to higher RMSE and lower $R^{2}$ in both LUE model and BEPS model. The $t$ test showed significant difference

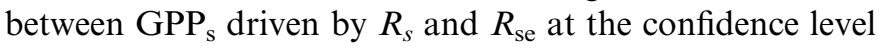
of $0.05(p=0.019)$ for LUE model, and significant difference at the confidence level of $0.01(p<0.001)$ for BEPS model.

For the LUE model, difference between two $\mathrm{GPP}_{\mathrm{s}}$ data (driven by $R_{S}$ and $R_{\mathrm{se}}$ ) was directly related to the difference of $R_{s}$ and $R_{\text {se }}$ due to the linear algorithm in the model. The $\mathrm{GPP}_{\mathrm{s}}$ driven by $R_{\mathrm{se}}$ shows more frequent overestimation during non-growing season (November-April) and more frequent underestimation in growing season (May-October) than that driven by $R_{s}$ (Fig. 9a). The MBE values ranged from $-0.81 \mathrm{~g} \mathrm{C} \mathrm{m}^{-2}$ day $^{-1}$ (relative MBE $-11.23 \%$, in June 2003 ) to $0.51 \mathrm{~g} \mathrm{C} \mathrm{m}^{-2}$ day $^{-1}$ (relative MBE 9.68\%, in April 2005). The RMSE ranged from $0.39 \mathrm{~g} \mathrm{C} \mathrm{m}^{-2}$ day $^{-1}$ (relative RMSE $48 \%$, in January 2005 ) to $1.32 \mathrm{~g} \mathrm{C} \mathrm{m}^{-2} \mathrm{day}^{-1}$ (relative RMSE $18 \%$, in June 2003). The differences between two $\mathrm{GPP}_{\mathrm{s}}$ data from LUE model were closely related to atmospheric conditions.

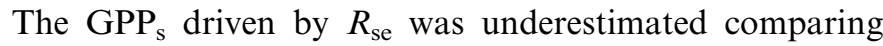
with that of $R_{s}$ when the clearness index was larger than 0.15 . The minimum difference existed during days with the clearness index in the range of $0.35-0.55$ (Fig. 9c). The largest difference occurred in days when the clearness index was larger than 0.7 with the MBE $-0.95 \mathrm{~g} \mathrm{C} \mathrm{m}^{-2} \mathrm{day}^{-1}$ (relative $\mathrm{MBE}-12 \%$ ), and the largest RMSE $1.54 \mathrm{~g} \mathrm{C} \mathrm{m}^{-2}$ day $^{-1}$ (relative RMSE 34\%) when the clearness index was in the range of $0.35-0.4$.

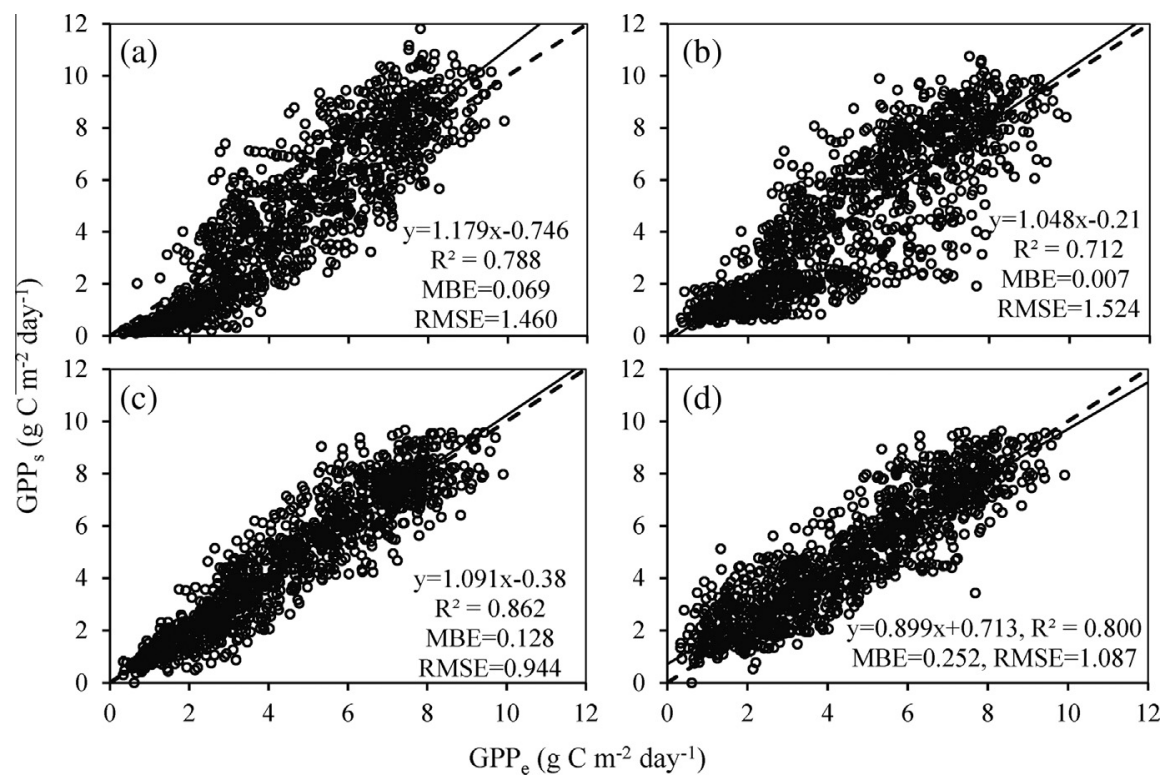

Fig. 8. Validation of GPP simulations driven by the observed solar radiation $\left(R_{s}\right)$ and estimated solar radiation $\left(R_{\mathrm{se}}\right)$ with LUE model and BEPS model at Qianyanzhou eddy tower site. (a) and (b) are LUE model driven by $R_{s}$ and $R_{\mathrm{se}}$; (c) and (d) are BEPS model driven by $R_{s}$ and $R_{\mathrm{se}}$. Dashed lines show the 1:1 line. Solid lines show the regression line. (GPP ${ }_{\mathrm{s}}$ : simulated GPP by LUE and BEPS models; GPP $P_{\mathrm{e}}$ estimated GPP from eddy tower measurements). 

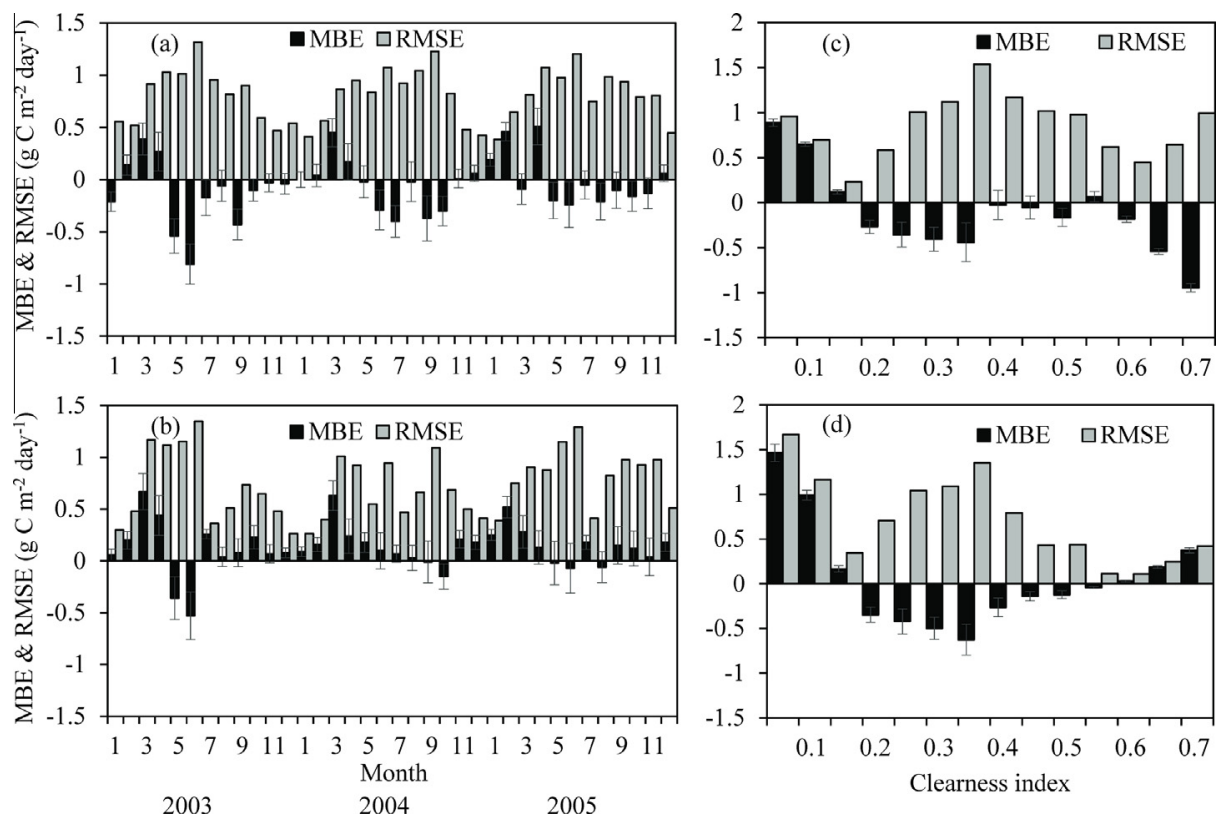

Fig. 9. Comparison of GPP simulated by LUE and BEPS model using observed solar radiation $\left(R_{s}\right)$ and estimated solar radiation $\left(R_{\mathrm{se}}\right)$. (a) and (b) are changes of MBE and RMSE for LUE model and BEPS model with months, respectively, (c) and (d) are changes of MBE and RMSE for LUE model and BEPS model with clearness index, respectively. The error bars denote the standard error of the mean.

$R_{\text {se }}$ had different impacts on GPP in BEPS model comparing with that of LUE model. The time of the largest difference in two $\mathrm{GPP}_{\mathrm{s}}$ sets was in late spring and early summer with the GPP driven by $R_{\text {se }}$ always being larger than that of $R_{s}$ (Fig. 9b). The MBE values ranged from $-0.53 \mathrm{~g} \mathrm{C} \mathrm{m}^{-2}$ day $^{-1}$ (relative MBE $-6 \%$, in June 2003) to $0.67 \mathrm{~g} \mathrm{C} \mathrm{m}^{-2} \mathrm{day}^{-1}$ (relative $\mathrm{MBE} 20 \%$, in March 2003). The RMSE values ranged from $0.26 \mathrm{~g} \mathrm{C} \mathrm{m}^{-2}$ day $^{-1}$ (relative RMSE 19\%, in January 2004) to $1.35 \mathrm{~g} \mathrm{C} \mathrm{m}^{-2} \mathrm{day}^{-1}$ (relative RMSE 16\%, in June 2003). $R_{\mathrm{se}}$ induced much difference in the daily $\mathrm{GPP}_{\mathrm{s}}$ when the clearness index was less than 0.1 with MBE and RMSE values of larger than $0.99 \mathrm{~g} \mathrm{C} \mathrm{m}^{-2} \mathrm{day}^{-1}$ (relative $\mathrm{MBE}>52 \%$ ) and $1.16 \mathrm{~g} \mathrm{C} \mathrm{m}^{-2} \mathrm{day}^{-1}$ (relative RMSE $>62 \%$ ) (Fig. 9d). Days when the clearness index was in the range of 0.22 $0.55, \mathrm{GPP}_{\mathrm{s}}$ driven by $R_{\mathrm{se}}$ was underestimated with MBE ranged from $-0.04 \mathrm{~g} \mathrm{C} \mathrm{m}^{-2}$ day $^{-1}$ to $-0.35 \mathrm{~g} \mathrm{C} \mathrm{m}^{-2}$ day $^{-1}$ (relative $\mathrm{MBE}-0.7 \%$ to $10 \%$ ) and $\mathrm{RMSE}$ ranged from $0.11 \mathrm{~g} \mathrm{C} \mathrm{m}^{-2}$ day $^{-1}$ to $1.35 \mathrm{~g} \mathrm{C} \mathrm{m}^{-2}$ day $^{-1}$ (relative RMSE $2-22 \%$ ). When the clearness index was large than 0.60 , the $R_{\mathrm{se}}$-based GPP $\mathrm{S}_{\mathrm{s}}$ was overestimated comparing with that of $R_{s}$ although $R_{\mathrm{se}}$ was underestimated.

\section{Discussion}

\subsection{The performance of sunshine duration based radiation estimation}

$R_{S}$ is the mainly limitation of photosynthesis in subtropical area of China, where is characterized by wet and warm summer and dry and mild winter with complex aerosolcloud-precipitation interactions. The heavy clouds, aerosol and frequent rainy days considerably influence the radiation estimation quality as the sunshine recorder is insensitive to the low radiation and the actual threshold depends on the humidity of the recording card (Besharat et al., 2013; Suehrcke et al., 2013). Previous study also found that various radiation products including reanalysis data (MERRA, ECMWF, NCEP) and satellite-derived products (GLASS, ISCCP) showed low correlation and large product errors in south China, resulting in large uncertainties in the GPP simulations driven by those data (Cai et al., 2014). The $R^{2}$ values of $R_{\mathrm{se}}$ in this study were higher than that reported by Liu et al. (2009b) based on sunshine duration with the $R^{2}$ varied between 0.61 and 0.89 with an average of 0.82 among 31 stations in China. The non-systematic estimation error expressed in terms of RMSE at Qianyanzhou site was $2.18 \mathrm{MJ} \mathrm{m}^{-2}$ day $^{-2}$ (relative RMSE 20\%), within the range reported by Supit and Van Kappel (1998), i.e. 1.4-5.0 $\mathrm{MJ} \mathrm{m}^{-2} \mathrm{day}^{-2}$, but a little higher than reported by Trnka et al. (2005) with the RMSE values between 1.4 and $1.8 \mathrm{MJ} \mathrm{m}^{-2}$ day $^{-1}$ (13.0$17.9 \%)$.

The widely and long-time availability of sunshine duration plays an irreplaceable role in validating radiation products and identifying historical impacts of changing radiation on carbon budget. Many studies considered the uniform systematic error in input $R_{\text {se }}$ to study their impacts on terrestrial ecosystem carbon simulation (Feng et al., 2007; Yan et al., 2011). In reality, the error of $R_{\mathrm{se}}$ varies greatly during individual months (even days) depending on the study area and cloud cover conditions. According to our test, $R_{\mathrm{se}}$ was overestimated during non-growing season with lower clearness index days and underestimated during the growing season with higher clearness index days. This was also observed in Czech and Austria by 
Trnka et al. (2007) and Trnka et al. (2005), which showed the $R_{\text {se }}$ yielded a relative MBE of more than $15 \%$, and showed an obviously overestimated $R_{\mathrm{se}}$ in November, December and January (by 10-20\%). These inaccuracies in the $R_{\text {se }}$ could be attenuated or multiplied owing to the different distribution characteristic of clearness index in different seasons.

The error in $R_{\text {se }}$ had direct impact on diffuse radiation estimation, and induced considerable difference between two $R_{d}$ data estimated from $R_{\mathrm{se}}$ and $R_{s}$. Although a logistic relationship between diffuse radiation fraction and clearness index could be established, $R_{\text {se }}$ led to the $R^{2}$ and RMSE of the estimated $R_{d}$ from 0.90 and $1.07 \mathrm{MJ} \mathrm{m}^{-2}$ day $^{-1}$ to 0.67 and $1.94 \mathrm{MJ} \mathrm{m}^{-2}$ day $^{-1}$, implying that the quality of solar radiation had serious impact on $R_{d}$ estimation. The relationship between $R_{d}$ and sunshine duration can be directly established, and might improve the $R_{d}$ estimation (Suehrcke et al., 2013). However, this is out of our scope as many ecosystem models only take $R_{s} / R_{\text {se }}$ as input data, and here we focused on the error propagation of $R_{\mathrm{se}}$ to $R_{d}$ and GPP estimation. The changes of $R_{s}, R_{b}$ and $R_{d}$ with clearness index according to the established logistic relationship can clearly depict the error propagate process (Fig. 10). Under constant solar radiation at the top of the atmosphere, overestimated $R_{\mathrm{se}}$ leads to an overestimation in both $R_{\mathrm{de}}$ and $R_{b}$ when the clearness index is low $(<0.43)$, and the underestimated $R_{\mathrm{se}}$ causes an overestimation in $R_{\mathrm{de}}$ and underestimation in $R_{b}$ when the clearness index is high $(>0.43)$. Therefore, the MBE of $R_{\mathrm{de}}$ is consistent with that of $R_{\mathrm{se}}$ when the clearness index is less than 0.43 , but become inconsistent when the clearness index is larger than 0.43 .

\subsection{Impacts of estimated radiation on GPP simulations}

The impacts of $R_{\mathrm{se}}$ on GPP varied in LUE and BEPS models due to the different algorithms between $R_{s}$ and photosynthesis. For LUE model, GPP has linear relationship with $R_{s}$ and the error of $R_{\mathrm{se}}$ directly propagates into GPP simulation. In the case of BEPS model, the error in $R_{\text {se }}$

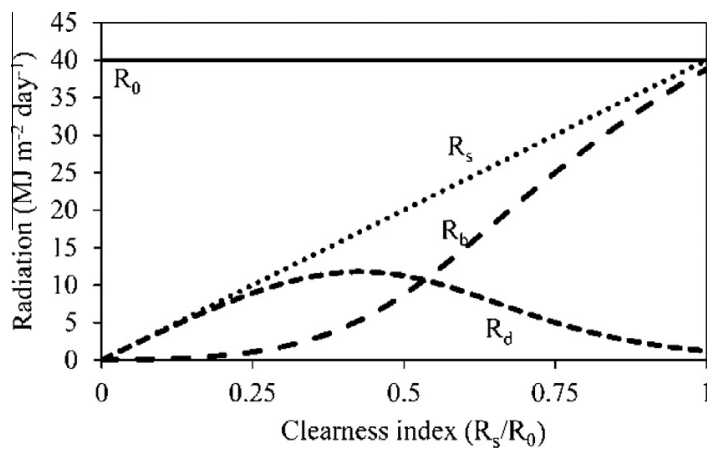

Fig. 10. Changes of solar radiation at the surface $\left(R_{S}\right)$, direct radiation $\left(R_{b}\right)$ and diffuse radiation $\left(R_{d}\right)$ with clearness index $\left(R_{s} / R_{0}\right)$ under the condition of solar radiation at the top of the atmosphere $\left(R_{0}\right)$ equal to $40 \mathrm{MJ} \mathrm{m}^{-2}$ day $^{-1}$. has complicated impacts on $\mathrm{GPP}_{\mathrm{s}}$ because the sunlit and shaded leaves react differently to $R_{S}$ variations under various sky conditions (Knohl and Baldocchi, 2008; Mercado et al., 2009). Ecosystem models that include multilayer canopies can capture the response of ecosystems to diffuse light (Alton et al., 2007). Recently, a two-leaf LUE model had been developed to improve the calculation of GPP under different sky clearness conditions (He et al., 2013). These models are strongly sensitive to small changes in incident radiation and uncertainties in radiation products, especially in these subtropical areas under frequently low-radiation conditions.

Our results show that the impact of $R_{\mathrm{se}}$ on $\mathrm{GPP}_{\mathrm{s}}$ is mainly consistent with that on $R_{\mathrm{de}}$ for the BEPS model. According to the established relationship between $R_{d}$ and $R_{s}$, the underlying mechanism can be understood: under extremely low clearness index conditions $(<0.15)$, both sunlit and shaded GPP ${ }_{\mathrm{s}}$ are overestimated because of the overestimated $R_{\text {se }}$ induces the $R_{b}$ and $R_{d}$ overestimated. When the clearness index is in the range of $0.15-0.43$, both sunlit and shaded GPP are underestimated due to the reduced $R_{d}$ and $R_{b}$ accompanied by underestimated $R_{\mathrm{se}}$. When the clearness index ranges from 0.43 to 0.55 , the overestimated $R_{\mathrm{se}}$ leads to $R_{\mathrm{de}}$ underestimated and $R_{b}$ overestimated, and

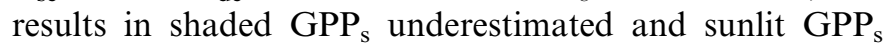
overestimated. Under extremely high clearness index $(>0.55)$, the shaded GPP is overestimated because of the overestimated $R_{\mathrm{de}}$ accompanied by the underestimated $R_{\mathrm{se}}$. Radiation variations on sunlit leaves do not initially result in a substantial change in leaf level photosynthesis as their radiation saturated. Shaded leaves, however, operate on the linear part of the light response curve and therefore respond sensitively to radiation uncertainties (Knohl and Baldocchi, 2008). As a result, errors in $R_{\text {se }}$ would have more significant impact on shaded leaves and definitely influence the shaded $\mathrm{GPP}_{\mathrm{s}}$ and total $\mathrm{GPP}_{\mathrm{s}}$.

\section{Conclusions}

While estimated daily solar radiation from sunshine duration data were widely used to simulate carbon budget in many ecosystem models, the impacts of its potential inaccuracy on GPP in forest ecosystem were rarely investigated. Results of this study executed in a subtropical plantation of China revealed (1) that estimated daily solar radiation from sunshine duration did not show significant difference with observed solar radiation; (2) calculated diffuse radiation based on estimated solar radiation is significantly different with that of observed solar radiation; (3) simulated daily GPP driven by estimated solar radiation is significantly different with that of observed solar radiation driven. The mean bias error ranges from $-11 \%$ to $10 \%$ for LUE (big-leaf) model, and from $-6 \%$ to $20 \%$ for BEPS (two-leaf) model depending on the month of a year. Our results also indicate that error in estimated solar radiation might aggregate or counteract for GPP simulation in different models and time scales. The estimated solar 
radiation from sunshine duration could partly conceal the underestimation and overestimation of GPP under extreme low and high clearness index, which is common in many LUE-based GPP models. In the case of BEPS model, the overestimation under low clearness index and underestimation under high clearness index both induced overestimation of diffuse radiation, and induced an overestimated GPP. Therefore, cautions should be taken when estimated solar radiation is used for site-specific ecosystem model calibrations or simulating the impacts of changing solar radiation on carbon budget. There is a great need for further research aiming at the development of more precise method to estimate solar radiation and diffuse radiation for these extremely high/low clearness index days in subtropical areas.

\section{Acknowledgements}

This study was supported by the Special Climate Change Fund (CCSF201412), the National Natural Science Foundation of China (41271211), Zhejiang A \& F University Research and Development Fund (2014FR084). The authors acknowledge the anonymous referees for their valuable comments.

\section{References}

Abraha, M.G., Savage, M.J., 2008. Comparison of estimates of daily solar radiation from air temperature range for application in crop simulations. Agric. Forest Meteorol. 148, 401-416.

Adaramola, M.S., 2012. Estimating global solar radiation using common meteorological data in Akure, Nigeria. Renew. Energy 47, 38-44.

Almorox, J.y., Hontoria, C., 2004. Global solar radiation estimation using sunshine duration in Spain. Energy Convers. Manage. 45, 1529-1535.

Alton, P.B., Ellis, R., Los, S.O., North, P.R., 2007. Improved global simulations of gross primary product based on a separate and explicit treatment of diffuse and direct sunlight. J. Geophys. Res., 112.

Angstrom, A., 1924. Solar and terrestrial radiation. Report to the international commission for solar research on actinometric investigations of solar and atmospheric radiation. Q.J. Roy. Meteorol. Soc. $50,121-126$.

Bakirci, K., 2009. Correlations for estimation of daily global solar radiation with hours of bright sunshine in Turkey. Energy 34, 485-501.

Besharat, F., Dehghan, A.A., Faghih, A.R., 2013. Empirical models for estimating global solar radiation: a review and case study. Renew. Sust. Energy Rev. 21, 798-821.

Boland, J., Ridley, B., Brown, B., 2008. Models of diffuse solar radiation. Renew. Energy 33, 575-584.

Cai, W., Yuan, W., Liang, S., Zhang, X., Dong, W., Xia, J., Fu, Y., Chen, Y., Liu, D., Zhang, Q., 2014. Improved estimations of gross primary production using satellite-derived photosynthetically active radiation. J. Geophys. Res.: Biogeosci. 119, 110-123.

Chen, J., Liu, J., Cihlar, J., Goulden, M., 1999. Daily canopy photosynthesis model through temporal and spatial scaling for remote sensing applications. Ecol. Model 124, 99-119.

Chen, J.M., Deng, F., Chen, M., 2006. Locally adjusted cubic-spline capping for reconstructing seasonal trajectories of a satellite-derived surface parameter. IEEE Trans. Geosci. Remote Sens. 44, 2230-2238.

Chen, J.M., Mo, G., Pisek, J., Liu, J., Deng, F., Ishizawa, M., Chan, D., 2012. Effects of foliage clumping on the estimation of global terrestrial gross primary productivity. Global Biogeochem. Cycles 26, GB1019.

Cotfas, D.T., Cotfas, P.A., Kaplani, E., Samoila, C., 2014. Monthly average daily global and diffuse solar radiation based on sunshine duration and clearness index for Brasov, Romania. J. Renew. Sust. Energy 6.

Cramer, W., Kicklighter, D., Bondeau, A., Iii, B.M., Churkina, G., Nemry, B., Ruimy, A., Schloss, A., 2001. Comparing global models of terrestrial net primary productivity (NPP): overview and key results. Global Change Biol. 5, 1-15.

Deng, F., Chen, J.M., Plummer, S., Chen, M., Pisek, J., 2006. Algorithm for global leaf area index retrieval using satellite imagery. IEEE Trans. Geosci. Remote Sens. 44, 2219-2229.

Erbs, D., Klein, S., Duffie, J., 1982. Estimation of the diffuse radiation fraction for hourly, daily and monthly-average global radiation. Sol. Energy 28, 293-302.

Farquhar, G., von Caemmerer, S.v., Berry, J., 1980. A biochemical model of photosynthetic $\mathrm{CO}_{2}$ assimilation in leaves of $\mathrm{C}_{3}$ species. Planta 149 , 78-90.

Feng, X., Liu, G., Chen, J., Chen, M., Liu, J., Ju, W., Sun, R., Zhou, W., 2007. Net primary productivity of China's terrestrial ecosystems from a process model driven by remote sensing. J. Environ. Manage. 85, $563-573$.

Garcia y Garcia, A., Guerra, L.C., Hoogenboom, G., 2008. Impact of generated solar radiation on simulated crop growth and yield. Ecol. Model 210, 312-326.

He, M., Ju, W., Zhou, Y., Chen, J., He, H., Wang, S., Wang, H., Guan, D., Yan, J., Li, Y., Hao, Y., Zhao, F., 2013. Development of a two-leaf light use efficiency model for improving the calculation of terrestrial gross primary productivity. Agric. Forest Meteorol. 173, 28-39.

Jarvis, P., Leverenz, J., 1983. Productivity of temperate, deciduous and evergreen forests. In: Physiological Plant Ecology, IV. Springer, pp. 233-280.

Ju, W., Gao, P., Wang, J., Zhou, Y., Zhang, X., 2010a. Combining an ecological model with remote sensing and GIS techniques to monitor soil water content of croplands with a monsoon climate. Agric. Water Manage. 97, 1221-1231.

Ju, W., Wang, S., Yu, G., Zhou, Y., Wang, H., 2010b. Modeling the impact of drought on canopy carbon and water fluxes for a subtropical evergreen coniferous plantation in southern China through parameter optimization using an ensemble Kalman filter. Biogeosciences 7, 845-857.

Knohl, A., Baldocchi, D.D., 2008. Effects of diffuse radiation on canopy gas exchange processes in a forest ecosystem. J. Geophys. Res., 113.

Liu, B.Y., Jordan, R.C., 1960. The interrelationship and characteristic distribution of direct, diffuse and total solar radiation. Sol. Energy 4, 1-19.

Liu, J., Chen, J., Cihlar, J., Chen, W., 1999. Net primary productivity distribution in the BOREAS region from a process model using satellite and surface data. J. Geophys. Res. 104, 27735-27754.

Liu, X., Mei, X., Li, Y., Wang, Q., Jensen, J.R., Zhang, Y., Porter, J.R., 2009a. Evaluation of temperature-based global solar radiation models in China. Agric. Forest Meteorol. 149, 1433-1446.

Liu, X., Mei, X., Li, Y., Zhang, Y., Wang, Q., Jensen, J.R., Porter, J.R., 2009b. Calibration of the Angström-Prescott coefficients (a, b) under different time scales and their impacts in estimating global solar radiation in the Yellow River basin. Agric. Forest Meteorol. 149, 697-710.

Liu, Y., Ju, W., Chen, J., Zhu, G., Xing, B., Zhu, J., He, M., 2012. Spatial and temporal variations of forest LAI in China during 2000-2010. Chin. Sci. Bull. 57, 2846-2856.

Liu, Y., Zhou, Y., Ju, W., Wang, S., Wu, X., He, M., 2014. Impacts of droughts on carbon sequestration by China's terrestrial ecosystems from 2000 to 2011. Biogeosciences 11, 2583-2599.

Mercado, L.M., Bellouin, N., Sitch, S., Boucher, O., Huntingford, C., Wild, M., Cox, P.M., 2009. Impact of changes in diffuse radiation on the global land carbon sink. Nature 458, 1014-1017.

Moré, J.J., 1978. The Levenberg-Marquardt Algorithm: Implementation and Theory. Springer, pp. 105-116.

Ögelman, H., Ecevit, A., Tasdemirolu, E., 1984. A new method for estimating solar radiation from bright sunshine data. Sol. Energy 33, 619-625.

Pan, Y., Birdsey, R.A., Fang, J., Houghton, R., Kauppi, P.E., Kurz, W.A., Phillips, O.L., Shvidenko, A., Lewis, S.L., Canadell, J.G., 2011. 
A large and persistent carbon sink in the world's forests. Science 333, 988-993.

Phakamas, N., Jintrawet, A., Patanothai, A., Sringam, P., Hoogenboom, G., 2013. Estimation of solar radiation based on air temperature and application with the DSSAT v4.5 peanut and rice simulation models in Thailand. Agric. Forest Meteorol. 180, 182-193.

Pohlert, T., 2004. Use of empirical global radiation models for maize growth simulation. Agric. Forest Meteorol. 126, 47-58.

Polo, J., Gastón, M., Vindel, J.M., Pagola, I., 2015. Spatial variability and clustering of global solar irradiation in Vietnam from sunshine duration measurements. Renew. Sust. Energy Rev. 42, 1326-1334.

Pommerening, A., LeMay, V., Stoyan, D., 2011. Model-based analysis of the influence of ecological processes on forest point pattern formation - a case study. Ecol. Model 222, 666-678.

Potter, C.S., Randerson, J.T., Field, C.B., Matson, P.A., Vitousek, P.M., Mooney, H.A., Klooster, S.A., 1993. Terrestrial ecosystem production: a process model based on global satellite and surface data. Global Biogeochem. Cycles 7, 811-841.

Prescott, J., 1940. Evaporation from a water surface in relation to solar radiation. Trans. Roy. Soc. S. Aust. 64, 114-118.

Prince, S.D., Goward, S.N., 1995. Global primary production: a remote sensing approach. J. Biogeogr., 815-835.

Reindl, D., Beckman, W., Duffie, J., 1990. Diffuse fraction correlations. Sol. Energy 45, 1-7.

Richardson, A.D., Anderson, R.S., Arain, M.A., Barr, A.G., Bohrer, G., Chen, G., Chen, J.M., Ciais, P., Davis, K.J., Desai, A.R., Dietze, M.C., Dragoni, D., Garrity, S.R., Gough, C.M., Grant, R., Hollinger, D.Y., Margolis, H.A., McCaughey, H., Migliavacca, M., Monson, R.K., Munger, J.W., Poulter, B., Raczka, B.M., Ricciuto, D.M., Sahoo, A.K., Schaefer, K., Tian, H., Vargas, R., Verbeeck, H., Xiao, J., Xue, Y., 2012. Terrestrial biosphere models need better representation of vegetation phenology: results from the North American carbon program site synthesis. Global Change Biol. 18, 566-584.

Rivington, M., Matthews, K.B., Bellocchi, G., Buchan, K., 2006. Evaluating uncertainty introduced to process-based simulation model estimates by alternative sources of meteorological data. Agr. Syst. 88, 451-471.

Rivington, M., Miller, D., Matthews, K.B., Russell, G., Bellocchi, G., Buchan, K., 2008. Evaluating regional climate model estimates against site-specific observed data in the UK. Climatic Change 88, 157-185.

Running, S.W., Coughlan, J.C., 1988. A general model of forest ecosystem processes for regional applications I. Hydrologic balance, canopy gas exchange and primary production processes. Ecol. Model 42, 125-154.

Running, S.W., Thornton, P.E., Nemani, R., Glassy, J.M., 2000. Global terrestrial gross and net primary productivity from the Earth observing system. Methods Ecosyst. Sci., 44-57.

Sprintsin, M., Chen, J.M., Desai, A., Gough, C.M., 2012. Evaluation of leaf-to-canopy upscaling methodologies against carbon flux data in North America. J. Geophys. Res., 117.
Suehrcke, H., Bowden, R.S., Hollands, K.G.T., 2013. Relationship between sunshine duration and solar radiation. Sol. Energy 92, 160 171.

Supit, I., Van Kappel, R., 1998. A simple method to estimate global radiation. Sol. Energy 63, 147-160.

Trnka, M., Eitzinger, J., Kapler, P., Dubrovský, M., Semerádová, D., Žalud, Z., Formayer, H., 2007. Effect of estimated daily global solar radiation data on the results of crop growth models. Sensors 7, 23302362.

Trnka, M., Žalud, Z., Eitzinger, J., Dubrovský, M., 2005. Global solar radiation in Central European lowlands estimated by various empirical formulae. Agric. Forest Meteorol. 131, 54-76.

Wang, J., Wang, E., Yin, H., Feng, L., Zhao, Y., 2015. Differences between observed and calculated solar radiations and their impact on simulated crop yields. Field Crops Res. 176, 1-10.

Xiao, X., Hollinger, D., Aber, J., Goltz, M., Davidson, E.A., Zhang, Q., Moore III, B., 2004. Satellite-based modeling of gross primary production in an evergreen needle leaf forest. Remote Sens. Environ. 89, 519-534.

Xie, Y., Kiniry, J.R., Williams, J.R., 2003. The ALMANAC model's sensitivity to input variables. Agric. Syst. 78, 1-16.

Yan, Y., Wang, S., Wang, Y., Wu, W., Wang, J., Chen, B., Yang, F., 2011. Assessing productivity and carbon sequestration capacity of subtropical coniferous plantations using the process model PnET-CN. J. Geogr. Sci. 21, 458-474.

Yorukoglu, M., Celik, A.N., 2006. A critical review on the estimation of daily global solar radiation from sunshine duration. Energy Convers. Manage. 47, 2441-2450.

Yu, G., Chen, Z., Piao, S., Peng, C., Ciais, P., Wang, Q., Li, X., Zhu, X., 2014. High carbon dioxide uptake by subtropical forest ecosystems in the East Asian monsoon region. Proc. Natl. Acad. Sci. 111, 4910-4915.

Yu, G., Song, X., Wang, Q., Liu, Y., Guan, D., Yan, J., Sun, X., Zhang, L., Wen, X., 2008. Water-use efficiency of forest ecosystems in eastern China and its relations to climatic variables. New Phytol. 177, 927-937.

Yuan, W., Cai, W., Xia, J., Chen, J., Liu, S., Dong, W., Merbold, L., Law, B., Arain, A., Beringer, J., Bernhofer, C., Black, A., Blanken, P.D., Cescatti, A., Chen, Y., Francois, L., Gianelle, D., Janssens, I.A., Jung, M., Kato, T., Kiely, G., Liu, D., Marcolla, B., Montagnani, L., Raschi, A., Roupsard, O., Varlagin, A., Wohlfahrt, G., 2014. Global comparison of light use efficiency models for simulating terrestrial vegetation gross primary production based on the LaThuile database. Agric. Forest Meteorol. 192-193, 108-120.

Yuan, W., Liu, S., Zhou, G., Zhou, G., Tieszen, L.L., Baldocchi, D., Bernhofer, C., Gholz, H., Goldstein, A.H., Goulden, M.L., Hollinger, D.Y., Hu, Y., Law, B.E., Stoy, P.C., Vesala, T., Wofsy, S.C., 2007. Deriving a light use efficiency model from eddy covariance flux data for predicting daily gross primary production across biomes. Agric. Forest Meteorol. 143, 189-207. 